\title{
Analysis Of Pharmaceutical Personnel Needs On Workload With Method Wisn (Workload Indicator Of Staffing Need) In Hospital Pharmaceutical Installation Hospital Royal Prima
}

\author{
Ary Denggan Syahputra Lubis ${ }^{1}$, Ermi Girsang ${ }^{2}$, Maya Sari Mutiara ${ }^{3}$, Ulina Karo-karo ${ }^{4 *}$ \\ 1,2,3,4 Master in Public Health, University Prima Indonesia, Medan North Sumatera,Indonesia \\ *Coresponden Author: \\ Email: ulinakarokaro@unprimdn.ac.id
}

\begin{abstract}
Hospital Pharmacy Installation (IFRS) is a function implementing unit that organizes all pharmaceutical service activities in hospitals (Permenkes, 2016). Hospital pharmacy services are one of the activities in hospitals that support quality health services. This is clarified in the Decree (SK) of the Minister of Health Number: 1333/Menkes/SK/XII/1999 concerning Hospital Service Standards, stating that hospital pharmacy services are an inseparable part of the hospital health care system that is patient-oriented, providing medicines, including clinical pharmacy services, which are affordable for all levels of society. This study aims to determine the need for health workers by calculating the ideal number of pharmacists based on the workload at the Hospital Royal Prima. This research is qualitative research using observation techniques, interview guidelines and document review. This study uses research informants where the informants used are the head pharmacist and pharmacist. Data analysis is the process of systematically searching and compiling data obtained from the results of field observations (work sampling), in-depth interviews and document reviews. From the results of research conducted that pharmaceutical workers use $85.3 \%$ of their working time with productive activities. Of the productive activities as much as $40.2 \%$ are direct productive activities while the rest are indirect productive activities, and as much as $23.8 \%$ of indirect productive activities are administrative activities, because in this study $8.7 \%$ were obtained as nonproductive activities and personal activities with the results of work sampling with the WINS method, it turns out that the number of pharmacists installed at the Hospital Royal Prima Marelan is smaller than the need for pharmaceutical workers installed at the Hospital Royal Prima Marelan.
\end{abstract}

Keywords: Pharmaceutical workforce workload, work sampling, WINS

\section{INTRODUCTION}

Hospitals are health service institutions that provide complete individual health services that provide inpatient, outpatient, and emergency services (Sondakh, Astuty and Uneputty, 2018). The health sector is no exception, hospitals have experienced very rapid development, especially in the city of Medan. Health efforts are all activities aimed at maintaining and improving health so that it will realize good and optimal health degrees for the community (Ronggonundarmo, Jati and Agushybana, 2019) With the development of information, people are becoming more selective and critical in choosing health facility services. Therefore, hospitals with efforts to improve health facility services in the community continue to provide quality services (Yulaika, 2018). One of them is the Royal Prima Marelan Hospital, which is one of the largest class C private hospitals and is a referral center for the community, especially in Marelan and the people of North Sumatra in general. Based on Law no. 44 of 2009 states that the hospital is a health service institution that provides inpatient, outpatient and emergency services. In addition, hospitals need human resources who have good knowledge as medical personnel. In addition to modern equipment, hospitals as places of public service should be supported by the availability of good human resources (Milasari, 2015).The high activity of health workers in serving patients will affect their work results. Due to the negative impact that can be caused by the workload overload, therefore there is a method of calculating the workload that needs to be carried out by a hospital in evaluating the effectiveness and efficiency of work as well as employee performance. One way to consider the number of health human resources is to analyze and calculate the workload (Wanri, Rahayu and Trigono, 2018).

And the need for manpower to support service activities at the installation pharmacy, so that service quality standards will be fully achieved and complaints will not be obtained (Ayu, 2020). One of them is the 
Hospital Pharmacy Installation (IFRS) which is a functional implementing unit that organizes all pharmaceutical service activities in hospitals (Permenkes, 2016). Hospital pharmacy services are one of the activities in hospitals that support quality health services. This is clarified in the Decree (SK) of the Minister of Health Number: 1333/ Menkes/SK/XII/1999 concerning Hospital Service Standards, stating that hospital pharmacy services are an inseparable part of the hospital health service system that is patient-oriented., providing medicines, including clinical pharmacy services, which are affordable for all levels of society (Ministry of Health RI, 2004) (Krisna, 2012).In previous studies, every year there is an increase in the number of prescriptions served by pharmacy but this increase in prescription services is not matched by an increase in the number of staff so that there is an increase in the workload in pharmacy. This increase in workload makes the waiting time for finished drugs longer than the quality indicators set by the hospital so that patient complaints against pharmaceutical services increase (Ronggonundarmo, Jati and Agushybana, 2019).

Planning the need for health workers is done by calculating the workload using the method workload indicators of staffing needs (WISN). The WISN method is used to calculate the need for health workers based on the workload of health workers with activity standards applied to each activity component (WHO, 2010). The WISN method is a method of calculating the need for health human resources based on the workload and there are five steps carried out in this method which is a description of each step of the activity, namely: determining the available working time; determine the work unit and category of Human Resources; prepare workload standards; compiling standards of leeway and calculating the need for labor per work unit (Ministry of Health, 2004) (Sinaga, 2016). The activity carried out in this method is to calculate how many health workers (from various types of personnel) are needed in a health service facility based on the current workload so that it is clear which units have excess or shortage of staff (Risakina, 2018). Based on research conducted by (Annisa Susanto, Mansur and Djauhari, 2017) Stating that, the results of the study obtained that the WISN ratio value was 0.4. The ratio $<1$ which means that the current amount of energy is smaller than the required power. So that it can be said that the current condition of UMM IFRS is a shortage of pharmacists.Based on the description that has been explained, the researchers are interested in analyzing the need for pharmacists on the workload with the WISN method (Workload Indicator Of Staffing Need) At the Pharmacy Installation of the Royal Prima Marelan Hospital, which will relate to the needs and availability of the number of health workers and provide health services.

\section{LITERATURE REVIEW}

\subsection{Definition of Pharmaceutical Services}

Pharmacy service is a process of organizing all pharmaceutical activities intended for hospital purposes, such as manufacturing, including quality control of pharmaceutical preparations, securing procurement, storage and distribution of drugs, drug management, drug services based on doctor's prescriptions, drug information services, and drug development. medicinal ingredients and traditional medicine (Fahrizal, 2016).

\subsection{Hospital Pharmacy Installation (IFRS)}

Hospital pharmacy installation (IFRS) is defined as a department or unit or part of a hospital led by a pharmacist and assisted by several pharmacists who meet the requirements of applicable laws and regulations and are professionally competent, the place or facility for the administration is responsible. responsible for all work and complete services, including planning; procurement; production; storage of medical supplies/pharmaceutical preparations; dispending drugs based on prescriptions for inpatients and outpatients; quality control; and controlling the distribution and use of all medical supplies in hospitals; general and specialist clinical pharmacy services, including direct service to patients and clinical services are the overall hospital program (Sondakh,Services for pharmacy activities in hospitals include the supply and distribution of all pharmaceutical products, as well as providing information and quality assurance related to the use of drugs. The definition of pharmacy activity services is (Maulana, 2017): 
a. Procurement and inventory system

b. Drug manufacture, including repackaging as needed and available facilities based on Good Medicine Manufacturing Practices

c. Assist in the implementation of an efficient distribution system, both for inpatients and outpatients,

d. Providing better drug information to hospital staff and patients

e. Assist in the implementation of clinical pharmacy, including monitoring of drugs in dosage, indications, effectiveness, side effects and prices

f. Implementation of education, including continuing education for pharmacy staff as well as pharmacy practicum for pharmacy students and postgraduate pharmacy students

IFRS Human Resources

According to the Decree of the Minister of Health of the Republic of Indonesia No. 1197 of 2004 concerning Standards for Pharmaceutical Services in Hospitals, Hospital Pharmacy Service Personnel are human resources who carry out pharmaceutical work in hospitals which are included in the hospital organization chart with the following requirements:

a. Registered with the Ministry of Health

b. Registered with the Professional Association

c. Have a work permit.

d. Have a placement decree

The administration of pharmaceutical services is carried out by professional pharmacists who are authorized by law, fulfilling the requirements both from the legal aspect, educational strata, quality and quantity with guarantees of certainty that there will be an increase in knowledge, skills and professional attitudes in order to maintain the quality of the pharmaceutical profession (Ministry of Health, 2004).

\subsection{Pharmaceutical Service Quality}

Quality control is a mechanism for monitoring and evaluating services provided, in a planned and systematic manner, so that opportunities for quality improvement can be identified and provide a mechanism for action to be taken so as to form a continuous quality improvement process for pharmaceutical services.In the Decree of the Minister of Health of the Republic of Indonesia No.1197/Menkes/ SK/X/2004 concerning Standards of Pharmaceutical Services in Hospitals, it is explained that the quality of hospital pharmacy services is pharmaceutical services that refer to the level of service excellence in generating patient satisfaction in accordance with the average level of satisfaction of the community, and its implementation is in accordance with the established professional service standards and in accordance with the code of ethics of the pharmacy profession. Pharmacy services must reflect the quality of high-quality pharmaceutical services, through good hospital pharmacy services.

a. Pharmaceutical services are involved in the quality control program for hospital services.

b. The quality of pharmaceutical services must be evaluated periodically against concepts, needs, processes, and results in order to improve service quality.

c. Pharmacists are involved in planning the quality control program.

d. Quality control activities

\subsection{WISN method (work load indicators staff need)}

HR calculation method based on WISN is a method of calculating health human resources based on the real workload carried out by each category of health human resources in each work unit in health facilities. The advantages of this method are that it is easy to operate, easy to use, technically easy to implement, comprehensive and realistic (Depkes 2004). The disadvantage of this method is that because the input data required for the calculation procedure comes from the recapitulation of the activities of the work unit/institution where the calculated workforce works, the completeness of data recording and the neatness of data storage must absolutely be carried out in order to provide accuracy maximum accuracy of the calculation results (Shipp, 
1998). There are five steps for calculating HR based on WISN, namely determining available working time, determining work units and HR categories, compiling workload standards, compiling slack standards, and calculating labor requirements per work unit.

1) Set working time

The goal is to obtain an effective working time of one year for each category of HR working in hospital institutions.

The formula is Available Working Time $=\mathrm{A}-(\mathrm{B}+\mathrm{C}+\mathrm{D}+\mathrm{E}) \times \mathrm{F}$

Description :

A $=$ Working Days (number of working days/week)

$\mathrm{B}=$ Annual Leave

$\mathrm{C}=$ Education and Training

$\mathrm{D}=$ National Holiday

$\mathrm{E}=$ Work Absenteeism (according to the average absenteeism work for a period of 1 year, due to illness, absent from work with or without reason)

$\mathrm{F}=$ Working Time (working time in one day)

\subsection{Workload}

According to Kepmenkes No. 81/MENKES/SK/I/2004, workload is the number of types of work that must be completed by professional health workers in one year in one health service facility. Meanwhile, according to the same Ministry of Health, workload analysis is an effort to calculate the workload on a work unit by adding up all workloads and then dividing by the individual work capacity of the unit.Meanwhile, according to the Decree of the Minister of State Apparatus Empowerment number KEP/75/M.PAN/7/2004 regarding guidelines for calculating employee needs based on workload in the context of preparing civil servant formations, workload is a number of work targets or target results that must be achieved in one unit. time. Workload is the main aspect that forms the basis for calculating employee needs and needs to be determined through work unit programs which are further translated into job targets for each position. By knowing well how to calculate the workload, it is hoped that planning for the number and type of workforce can be carried out more rationally as needed. According to Ilyas (2011) to calculate the workload of personnel there are three ways that can be used, namely:

1. Work sampling

2. Time and motion study

3. Daily Log

\section{METHODS}

The type of research used is descriptive research with quantitative and qualitative data analysis, using a research design cross sectional. This study was to determine the workload in the pharmacy installation of the Hospital Royal Prima.The population in this study is the human resources (HR) of pharmacy services at the pharmacy installation of the Hospital Royal Prima with a total of 5 populations in the pharmacy installation of the Hospital Royal Prima.In accordance with the purpose of the study, the sample used in this study used total sampling, namely 1 principal pharmacist, 2 pharmacists, 1 pharmacist assistant and 1 drug warehouse officer at the pharmacy installation of the Hospital Royal Prima Marelan.

The data collection method used in this research is to use primary data and secondary data.

\section{a. Primary Data :}

\section{Observation (Observation)}

This is done by observing directly the daily life of the informants in carrying out their duties. where this method can help explain the data obtained through in-depth interview techniques or in other words carried out as a form of triangulation to ensure the validity of the data that has been obtained. 


\section{In-depth interview (in-depth interview)}

Interviews are used as a data collection technique to find out more in-depth things from respondents based on self-reports, self-reports and knowledge to obtain information from informants using interview guides. For a qualitative approach, researchers conducted in-depth interviews with the head of the pharmacy installation, pharmacists and pharmacist assistants at the pharmacy installation of the Royal Prima Marelan Hospital.

\section{b. Secondary Data:}

\section{Review Documents}

Document studies by collecting documents and data needed in research problems and then studied intensely so that they can support and add to the belief and evidence of an incident.The research instrument used in this study was an observation form which consisted of two types, namely a form for observing pharmacy service activities and a pharmacist's activity record. The form contains the serial number, day/date, activities carried out and duration of service activities. This form is then used for note-taking by observers. Instrument The other is a guideline for conducting in-depth interviews with pharmacists at the pharmacy installation of the Royal Prima Marelan Hospital.For the data analysis method in this study, data analysis was carried out to determine the workload in the pharmacy installation of the Royal Prima Hospital. First, find the average time needed to provide pharmaceutical services to customers at the pharmacy installation of the Royal Prima Marelan Hospital.Then after knowing the average time needed, it can be seen how much workload per shift is based on the amount of time. From this calculation, the energy requirement per day can be found, carried out using the WISN method (Workload Indicator Of Staffing Need) taking into account the time of pharmacy service per day, the time needed to provide pharmacy services and effective working hours per day at the pharmacy installation of the Royal Prima Marelan Hospital.

\section{ANALYZE AND RESULT.}

\subsection{Research Process}

The research was conducted at Hospital Royal Prima Marelan which is one of the type C private hospitals in the city of Medan. This hospital is located on Marelan Raya street Pasar II No. 187, Rengas Pulau, Marelan, Medan City, North Sumatra. It was carried out on December 06 - 09, 2021 and during the research process it was smooth and easy because at the time of the research there was good cooperation. especially the management of Hospital Royal Prima Marelan who strongly supports this research as one of the inputs for improving the quality of service at the pharmaceutical installation of RSU Royal Prima Marelan.

At the time of research observation to see the activities of pharmacists at the pharmacy installation of Hospital Royal Prima Marelan withwork sampling, the researcher emphasizes the principle of this work sampling is to prioritize the activities and activities carried out by pharmacists at the pharmacy installation of Hospital Royal Prima Marelan.Workload Analysis of Pharmacists at Pharmacy Insta at RSU Royal Prima Marelan.This study describes the activities and time used by pharmacists or pharmacists as implementers during observations using the form work sampling. The activities carried out are divided into four types, namely direct pharmacy staff activities, indirect pharmacy staff activities, personal activities and non-productive activities.

Table 1. Distribution of the Number of Pharmacy Workers in Pharmacy Institutions RSU Royal Prima Marelan

\begin{tabular}{lll}
\hline Gender & Amount & Percentage \\
\hline Man & 2 & 33.3 \\
Woman & 4 & 66.7
\end{tabular}

Table 1 illustrates that the average number of pharmacists for the male gender is 2 people with a percentage $(33.3 \%)$ and the average number of pharmacists for the female sex is 4 people with a percentage $(66.7 \%)$. ). 


\subsection{Total Time for Direct Pharmacists Activities}

The amount of time nursing activities were carried out was four days starting From December 06, 2021 to December 09, 2021, a pharmacy is installed and the results of the amount of time for pharmacy staff activities illustrate the large workload of pharmacists or direct pharmacy installation activities at RSU Royal Prima Marelan for four working days for 24 hours.

Tables 2. Total Time Activities of Direct Pharmacists

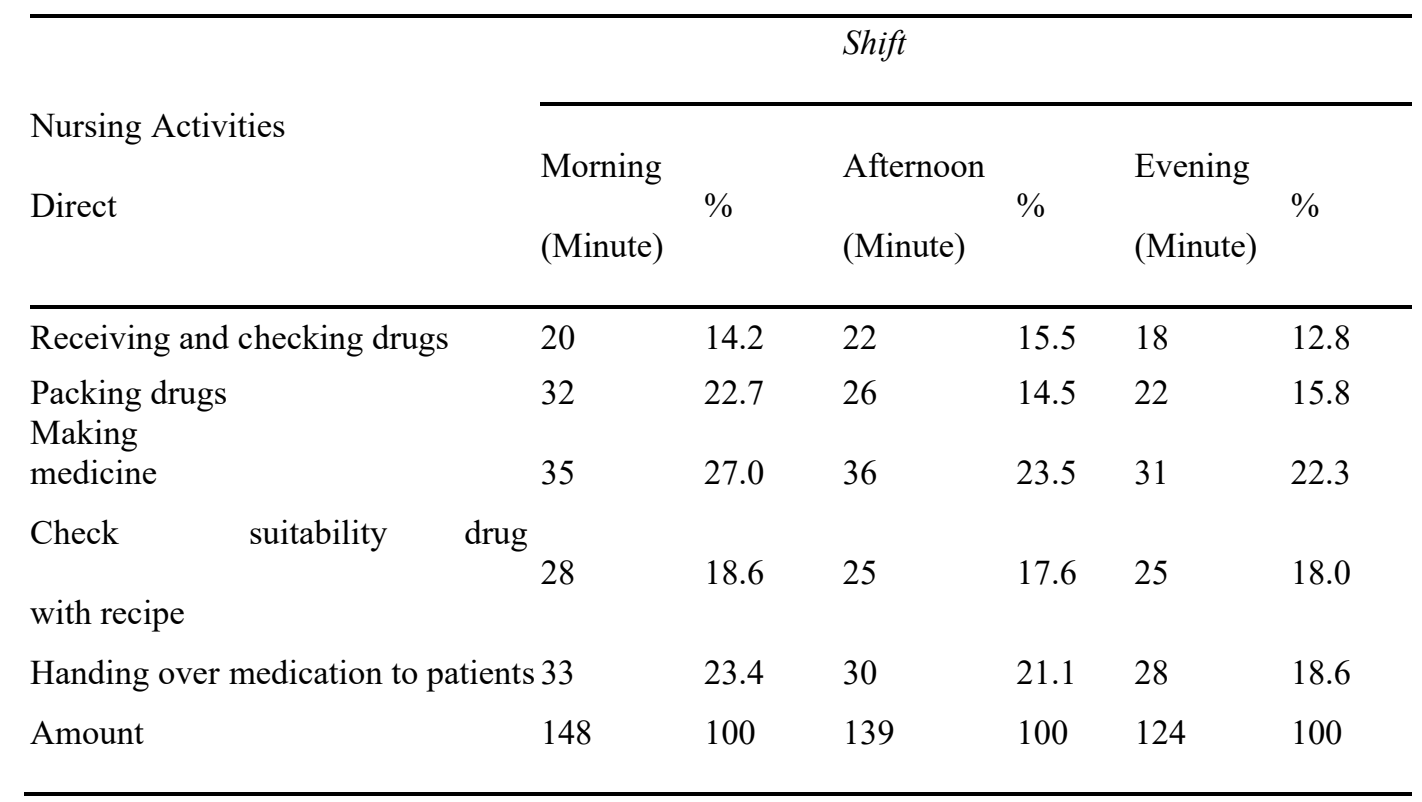

In tables 2 it is found that for the use of time for direct pharmacy staff activities for pharmacists who implement the most for 2 days are in shift Morning with a total activity time of 148 minutes with the most activity being dispensing medicine for 35 minutes (27.0\%). Second most time usage onshift afternoon of 139 minutes with the most activity i.e. mixing medicine as much as 36 minutes $(23.5 \%)$. The third most time use is inshift night, which is 124 minutes with the most activity, namely pharmacists dispensing drugs for 31 minutes $(21.8 \%)$.

\subsection{Total Time of Indirect Pharmacy Worker Activities}

The total time for nursing activities to be carried out for four days starting from December 06, 2021 to December 09, 2021, at the pharmacy installation at RSU Royal Prima Marelan, obtained the results of the amount of time for indirect nursing activities.

Tables 3. Total Time of Indirect Pharmacy Workers

\begin{tabular}{|c|c|c|c|c|c|c|}
\hline \multirow{2}{*}{$\begin{array}{l}\text { Nursing Activities } \\
\text { Direct }\end{array}$} & \multicolumn{6}{|c|}{ Shift } \\
\hline & $\begin{array}{l}\text { Morning } \\
\text { (Minute) }\end{array}$ & $\%$ & $\begin{array}{l}\text { Afternoon } \\
\text { (Minute) }\end{array}$ & $\%$ & $\begin{array}{l}\text { Evening } \\
\text { (Minute) }\end{array}$ & $\%$ \\
\hline $\begin{array}{l}\text { Collect and } \\
\text { Recipe }\end{array}$ & 20 & 14.2 & 22 & 15.5 & 18 & 12.8 \\
\hline Preparing medicine & 32 & 31.6 & 26 & 15.6 & 12 & 11.0 \\
\hline $\begin{array}{l}\text { Make a recap submission } \\
\text { drug claims for BPJS Checking the } \\
\text { suitability of BPJS claim } \\
\text { prescriptions }\end{array}$ & 43 & 21.9 & 48 & 28.7 & 32 & 29.4 \\
\hline
\end{tabular}


Recording fractures of goods/medicines Arranging drugs in the cupboard

Amount

$\begin{array}{llllll}33 & 23.4 & 30 & 21.1 & 28 & 18.6 \\ 28 & 18.6 & 26 & 14.5 & 30 & 21.0 \\ 210 & 100 & 201 & 100 & 142 & 100\end{array}$

In tables 3, it is found that the use of time for indirect nursing activities for implementing nurses in the inpatient room for two days is mostly in shift morning with a total activity time of 210 minutes with the most activities, namely Making a recap of filing a drug claim for BPJS for 43 minutes or $21.9 \%$. The second most time use is in shift afternoon with a total activity time of 201 minutes with the most activities, namely Checking the suitability of BPJS claim prescriptions of 49 minutes or $29.3 \%$. The third most time use is on the night shift with a total activity time of 142 minutes with the most activity, namely Making a recap of filing a drug claim for BPJS for 32 minutes or $29.4 \%$.

\subsection{Total Personal Activity Time}

The number of times nursing activities are carried out for four days starting from December 06, 2021 to December 09, 2021, at the pharmacy installation at RSU Royal Prima Marelan getting the results of personal activities can be seen in the following table:

Tables 4. Total Personal Activity Time

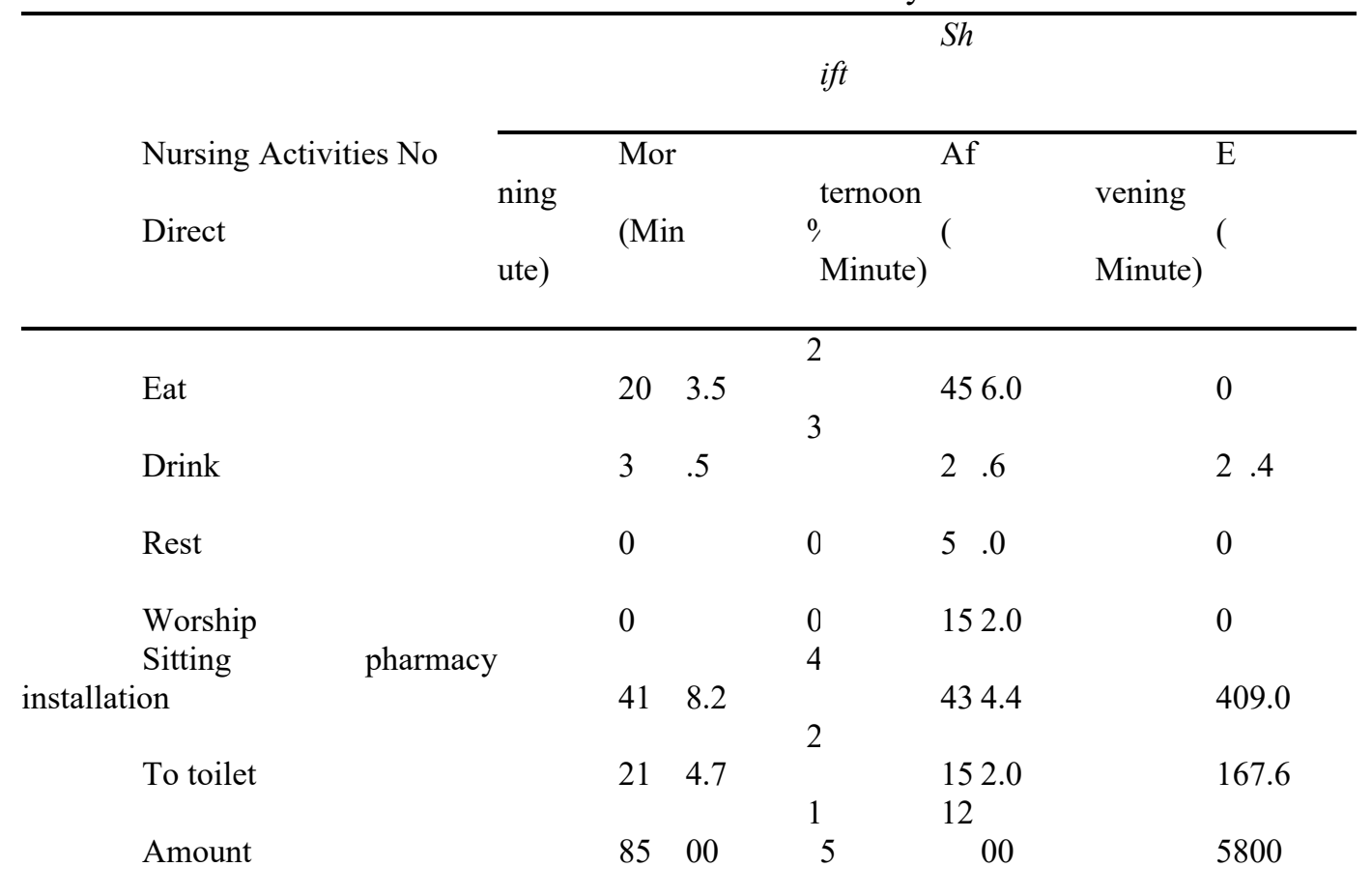

\subsection{Analysis of Nurse Workload in the Inpatient Room of Royal Prima General Hospital Medan.}

The workload of nurses in the inpatient room of the Royal Prima Merelan General Hospital was obtained by observing for 24 hours in three hours shift i.e. morning, afternoon and evening using the technique work sampling. With a total of 6 pharmacists. From the observations that have been made, it is known that the amount of time for direct activities is $36.7 \%$ and the amount of time for indirect nursing activities is $40.2 \%$, while the total time for personal activities is $23.1 \%$.Henceforth, indirect productive activities by researchers are included as a component of the nurse's workload because these activities are activities that cannot be avoided and are still related to the needs and interests of patients and nurses. If you add up the time of direct nursing activities, indirect nursing activities and personal activities as a nurse's workload, the proportion of time obtained is $85.3 \%$. 
The workload as an activity given to the implementing nurse at a hospital has an important role to determine the need for pharmaceutical personnel needed in the smooth completion of a job where the calculation of the workload requires a certain method or technique to suit the wishes of the hospital. This specific statement about the amount of time that should be devoted to carrying out certain activities under normal working conditions is often called labor standard work. This workload analysis technique is the use of ratios or standard staffing guidelines to determine the need for pharmacists. Workload analysis identifies both the number of pharmacists and the type needed to achieve hospital goals.Based on this, it is indeed a dilemma for the management of the Hospital Royal Prima in Medan because the number of patients admitted to the hospital cannot be ascertained. If the number of pharmacists is added according to the current workload, then there is a possibility that the number of workers will be excess when the workload will one day decrease. Therefore, a policy that is truly in accordance with the condition of the hospital is needed in order to become a superior hospital in service to the community.

\subsection{Amount of Manpower Required Based on Workload Using the WISN Method in the Inpatient Room of the Royal Prima Marelan General Hospital}

Based on the results of the study, it was found that the number of workers needed based on workload using the WISN method was 12.63 people in the inpatient room of Hospital Royal Prima.From the activities of these pharmacists, it is illustrated that they must be able to carry out their duties in order to be able to provide the best service to every patient who is treated without having to be burdened by a lack of labor. If the number of health workers does not match the existing workload, it is possible that maximum services cannot be implemented.

\section{CONCLUSION.}

Based on the results of the study it can be concluded as follows:

1. The total time spent on pharmacy staff during the observation was known that the use of time for direct nursing activities of implementing nurses in the inpatient room was $36.7 \%$, indirect nursing activities was $40.2 \%$ and personal activities was $23.1 \%$. This shows that the activities that are mostly carried out by pharmaceutical personnel are indirect labor activities. This is because nursing activities do not directly have to be carried out and completed in accordance with procedures.

2..The number of personnel required based on workload using the WISN method in the pharmacy installation of the Royal Prima Merelan General Hospital is 13 people.

\section{REFERENCES}

[1] Annisa Susanto, N., Mansur, M. and Djauhari, T. (2017) 'Needs Analysis Staff at the Pharmacy Installation of the University of Muhammadiyah Malang Hospital in 2016', Journal of Medicoeticolegal and Hospital Management, 6(2), pp. 82-89. doi: 10.18196/jmmr.6131.

[2] Ayu, IAS (2020) 'Analysis of the need for health workers in pharmaceutical installations in some hospitals with the method'.

[3] Fahrizal (2016) 'Analysis of the Implementation of Minimum Service Standards (SPM) for Homes Hospital in the Pharmacy Sector at the Pharmacy Installation of the Muara Teweh Regional General Hospital in 2016', Thesis of the Faculty of Pharmacy, Setia Budi University, 1, pp. 1-476.

[4] Krisna, M. (2012) 'Analysis of Workload and Manpower Needs in Installations Pharmacy of the Regional Mental Hospital of Lampung Province in 2012', Faculty of Public Health, University of Indonesia, pp. 25-27.

[5] Maulana, MSR (2017) 'INFLUENCE OF QUALITY OF PHARMACEUTICAL SERVICES ON THE DECISION TO REBUY MEDICINE IN THE PHARMACEUTICAL UNIT OF TK IV MADIUN HOSPITAL IN 2017 IS COLLECTED, ekp, 13(3), pp. 1576-1580.

[6] Milasari, RI (2015) 'Analysis of Pharmacy Workforce Needs Based on Burden Work in the Pharmacy Installation of the Bali Province Indra Hospital in 2015', Essay. 
[7] Nuryati, Pramono, AE and Wijayanti, A. (2013) 'Manpower Demand Planning Medical Records Using the Workload Indicators of Staffing Need (Wisn) Method at the Gondokusuman II Public Health Center, Yogyakarta City', Indonesian Journal of Health Information Management, 1(2). doi:10.33560/.v1i2.44.

[8] Parmita, RA (2017) 'CALCULATION OF RECORD POWER REQUIREMENTS MEDICAL USING THE WISN (WORKLOAD INDICATOR STAFFING NEED) METHOD IN DR. SOETARTO YOGYAKARTA IN 2016', 87(1,2), pp. 149-200.

[9] Risakina, I. (2018) 'Analysis of Nurse Needs in General and Children's Polyclinic Merdeka Health Center in Palembang City Using Workload Indicator Staffing Need (WISN) Method ABSTRACT'. 